\title{
KOLONI BURUNG CANGAK ABU (Ardea cinerea LINNAEUS) DI AREA BANDAR UDARA INTERNASIONAL ADISUTJIPTO YOGYAKARTA (Grey Heron Colony (Ardea cinerea Linnaeus) in Yogyakarta Adisutjipto International Airport
} Area)

\author{
Bambang Agus Suripto* dan Kukuh Oktarinaria* \\ Fakultas Biologi Universitas Gadjah Mada, Jln Teknika Selatan, Sekip Utara Yogyakarta.
}

*Penulis korespondensi. Tel: 06281392152242. Email: suriptobambang@ yahoo.com. Diterima: 21 November 2018

Disetujui: 20 Desember 2018

\begin{abstract}
Abstrak
Bird strike merupakan peristiwa tabrakan antara burung baik secara berkelompok maupun tunggal dengan pesawat terbang pada proses penerbangan. Kejadian bird strike dapat menyebabkan kecelakaan ringan hingga serius yang sangat merugikan secara ekonomi Sekalipun telah dilakukan bird control secara maksimal berdasarkan panduan yang tersedia, namun bird strike juga terkadang masih terjadi di Bandar Udara Internasional Adisutjipto Yogyakarta (JOG) dengan tingkat kerusakan pesawat dari berat sampai ringan. Salah satu jenis burung penyebab kejadian bird strike di kawasan ini adalah cangak abu. Tujuan penelitian ini adalah mengetahui besaran dan prilaku koloni burung cangak abu (Ardea cinerea) pengunjung area. Pengambilan data besaran koloni burung pengunjung dilakukan dengan penghitungan langsung (sensus); perilaku selama di lokasi antara lain waktu dan arah datang dan pergi serta aktivitas yang dilakukan burung cangak abu selama di area bandara diamati dan dicatat secara langsung. Semua data yang diperoleh dianalisis secara deskriptif-kualitatif dan diperbandingkan burung lain dan hasil penelitian lain sehingga dapat diperoleh gambaran yang jelas tentang mengapa koloni cangak abu tersebut menjadi pengunjung area bandara. Hasil penelitian menunjukkan. Keberadaan burung cangak abu di Bandara Adisutjipto berpotensi relatif terbesar menimbulkan kejadian bird strike dibanding burung jenis lainnya karena jumlah individu harian yang datang terbanyak, frekuensi kedatangannya tertinggi kedua setelah burung wallet, ukuran tubuhnya yang relatif terbesar, terbang rendah, terbang pelan dan manuvernya juga lamban serta terbang menyilang landasan. Kondisi lingkungan area runway bandara yang luas, lapang terbuka, ditutupi hijauan rerumputan, berangin, aman dari predator, sepi jauh dari kegiatan manusia dan lokasinya yang strategis diantara zona roosting/nesting dan zona foraging/feeding menjadi lokasi yang ideal bagi koloni cangak abu untuk melakukan kegiatan harian loafing. Pengelola bandara JOG perlu meningkatkan kewaspadaan terhadap kemungkinan peningkatan kehadiran burung cangak abu, dan perlu memperluas jangkauan pengelolaan populasi cangak abu di luar wilayah bandara.
\end{abstract}

Kata kunci: Bird strike, Bandara Internasional Adisutjipto, Cangak abu, Ardea cinerea, prilaku loafing.

\begin{abstract}
Bird strike is a bird collision event both in groups and singly with an aircraft in the flight process. Bird strike events can cause minor to serious accidents which are very detrimental to the economy. Although maximum bird control has been carried out based on the available guidelines, bird strikes also sometimes occur at Yogyakarta Adisutjipto International Airport (YAIA) with the level of aircraft damage from heavy to light. One type of bird that causes the bird strike incident at YAIA is grey heron. The purpose of this study was to determine the dayly individual number and behavior of the grey heron (Ardea cinerea), visitors to the YAIA area. Data collection on visitor bird colony size is carried out by direct count (census); behavior while in YAIA, including the time and direction of coming and going, and what the grey heron did during the airport area was observed and recorded directly. All data obtained were analyzed descriptively-qualitatively and compared to other birds and other research results so that a clear picture of why the colony of grey heron can be obtained as a visitor to the YAIA area. The results showed. the presence of grey heron (Ardea cinerea) at Adisutjipto Airport has the highest relative potential to cause bird strike events compared to other types of birds because the highest number of daily individuals, the second highest frequency of arrival after a glossy swiftlet, the largest relative body size, low flight, slow flight and maneuvers are also slow and fly across the runway. The YAIA runway area, which is wide, open and covered with grasses, windy, safe from predators, is quiet away from human activities and a strategic location between the roosting / nesting zone and the foraging / feeding zone makes it an ideal location for grey heron colonies to conduct colony of grey heron daily loafing activities. In conclusion, the manager of YAIA needs to increase awareness of the possibility of increasing the presence of grey herons, and it is necessary to broaden the scope of management of the grey heron population outside the YAIA region.
\end{abstract}

Keywords: Bird strike, Yogyakarta Adisutjipto International Airport, Grey heron, Ardea cinerea, loafing behavior. 


\section{PENDAHULUAN}

Bird strike adalah kejadian tabrakan burung baik secara berkelompok maupun tunggal pada pesawat terbang pada proses penerbangan. Kejadian bird strike dapat menyebabkan kecelakaan ringan hingga serius seperti pecahnya kaca kokpit pesawat sampai terbakarnya mesin pesawat akibatnya sangat merugikan secara ekonomi (Sodhi, 2002; Dove dkk, 2006). Data dari International Bird Strike Committee, 55 kejadian fatal telah terjadi antara tahun 1912 dan 2009, terdapat 108 buah pesawat rusak dan 277 penumpang meninggal. Selama penerbangan militer, korban jiwa dan kerusakan pesawat menunjukkan setidaknya 283 pesawat rusak, menyebabkan 141 kematian antara tahun 1959 dan 1999. Terkait kerusakan atau kegagalan struktur akibat fenomena tabrak burung rentan terjadi pada struktur permukaan luar pesawat udara. Komponen struktur tersebut berupa windshield, radome, fuselage skin/panels, fan blade maupun inlet engine (Sitompul dan Hanafi, 2017). Secara umum di Indonesia seperti dilaporakan oleh Agustono (2017) telah tercatat 41 kejadian bird strike (2013) dan 23 kejadian (2014), sementara di Bandar Udara International Ngurah Rai di Bali telah terjadi 7 kejadian bird strike (2011), 9 kejadian bird strike (2012) dan 6 kejadian bird strike (2013).

Di Indonesia, dalam rangka menjamin keselamatan penerbangan telah dikeluarkan beberapa regulasi. Ketentuan penggunaan lahan di sekitar Kawasan Keselamatan Operasi Penerbangan (KKOP) bandar udara harus memenuhi persyaratan antara lain tidak menyebabkan timbulnya bahaya burung (BSN, 2005), peraturan lain yang terkait dengan keselamatan bandara adalah UU Nomor 1 Tahun 2009 tentang Penerbangan;. PP Nomor 40 Tahun 2012 tentang Pembangunan dan Pelestarian Lingkungan Hidup Bandara; dan Peraturan Menteri Perhubungan Nomor KM44 tahun 2005 tentang Pemberlakuan SNI KKOP sebagai standar wajib. Pengaturan dari Pemerintah yang secara eksplisit menyebutkan teknik untuk mencegah terjadinya bird strike tertuang dalam Surat Edaran Direktorat Jenderal Perhubungan Udara nomor SE/0I/III/2009 tentang pencegahan bird strike di Bandar udara. Isinya antara lain mengingatkan dan memerintahkan kepada seluruh Kepala atau Pimpinan atau General Manager Bandar Udara agar melakukan manajemen dan modifikasi lingkungan untuk mencegah burung datang; menggunakan berbagai teknologi pengusir burung; melakukan penelitian mengenai jenis burung di dalam dan luar bandara agar dapat dilakukan upaya mencegah ketertarikan burung untuk datang secara tepat; dan berkoordinasi dengan pihak pemerintah daerah setempat dalam perencanaan tata ruang di sekitar bandar udara sehingga tidak menyebabkan burung datang atau beraktifitas di sekitar bandar udara.

Panduan untuk mengontrol populasi burung (bird control), yang tertuang dalam Surat Edaran nomor SE/0I/III/2009, telah dilaksanakan oleh Pihak Manajemen Bandara, namun ternyata masih banyak jenis burung yang mendatangi bandara di Indonesia. Misalnya, pada Selasa, 7 November 2017 di Bandara Internasional Adisutjipto Yogyakarta sempat mengalami penutupan atau runway closed pada pukul 05.00 hingga 07.30 WIB dan dibuka kembali pada pukul 07.35 WIB karena terjadinya peningkatan populasi burung (Pranyoto, 2017). PT Angkasa Pura I (Persero) mencatat bahwa burung penyebab bird strike di Bandar Udara Internasional Juanda adalah jenis cangak abu (Ardea cinerea), selain itu jenis yang berpotensi mengganggu penerbangan antara lain kuntul kerbau (Bubulcus ibis), blekok sawah (Ardeola speciosa), kowak malam abu (Nycticorax nycticorax) (Satriyono, 2008). Sekalipun telah dilakukan bird control secara maksimal, namun bird strike juga beberapa kali terjadi di Bandar Udara Internasional Adisutjipto Yogyakarta (JOG) dengan tingkat kerusakan pesawat dari berat sampai ringan. Burung cangak abu termasuk di antara 38 jenis burung yang dijumpai di area JOG yang juga menjadi penyebab bird strike selain jenis burung lainnya (Suripto dan Hendri, 2018). Bila terjadi tabrakan antara burung cangak abu dengan pesawat maka dampaknya akan relatif besar karena ukuran tubuhnya yang terbesar, $100 \mathrm{~cm}$ (McKinnon dkk, 1998), diantara jenis burung yang ditemukan di JOG. Namun sejauh ini belum belum diketahui berapa jumlah individu dari koloni cangak abu yang datang setiap hari, arah mana mereka datang dan pergi, dan aktivitas yang mereka lakukan selama berada di area bandara. Koloni adalah sekumpulan individu yang merupakan bagian atau anggota dari suatu dema, yaitu merupakan bagian dari populasi suatu jenis hewan yang mendiami suatu tempat dimana individu anggotan suatu spesies bisa saling berinteraksi langsung. Berdasarkan latar belakang tersebut maka perlu dipelajari frekuensi kedatangan koloni cangak abu di JOG, jumlah individu koloni yang datang setiap hari, dan kebiasaan atau prilakunya selama di JOG.

Tujuan penelitian ini adalah mengetahui besaran koloni dan kebiasan/aktivitas koloni cangak abu saat berada di area Bandara Internasional Adisutjipto Yogyakarta. Adapun manfaat hasil penelitian ini adalah sebagai masukan agar upaya teknis pengelolaan koloni pengunjung area Bandara Adisutjipto sehingga kejadian bird strike yang disebabkan oleh cangak abu bisa diminimalisasi atau bahkan bisa dicegah. 


\section{METODE PENELITIAN}

\section{Waktu dan Lokasi}

Lokasi penelitian di dalam area Bandar Udara Internasional Adisutjipto Yogyakarta (JOG). Kawasan ini berada Desa Maguwoharjo, Kecamatan Depok, Kabupaten Sleman, Daerah Istimewa Yogyakarta. Kawasan Bandara Adisutjipto Yogyakarta secara keseluruhan saat ini memiliki luas $\pm 1.830 .000 \mathrm{~m}^{2}(183 \mathrm{Ha})$ yang selama ini dimanfaatkan untuk penerbangan sipil dan penerbangan militer TNI-AU, yang dikelola oleh PT Angkasa Pura I (Persero). Penelitian dilaksanakan pada bulan Agustus - Oktober 2018.

\section{Alat}

Binokuler, camera digital, dan buku panduan untuk diidentifikasi jenis burung (McKinnon dkk, 1998).

\section{Prosedur}

\section{Pengambilan data}

a. Koloni burung cangak abu di Bandara Internasional Adisutjipto Yogyakarta

Pengambilan data cangak abu dan jenisjenis burung lainnya serta jumlah individu masing-masing jenis dilakukan dari Watchroom Airport Rescue \& Fire Fighting Station (ARFF). Pengamatan dilakukan pada pukul 07.00-09.00 WIB dan 14.30-16.30 WIB, dengan menggunakan binokuler dan kamera dengan durasi pengamatan kurang lebih selama 2 jam per sesi.

Setiap jenis burung yang teramati kemudian dicatat jumlah individunya dan diidentifikasi dengan buku panduan (McKinnon dkk., 1998). Jenis burung lain juga perlu diamati untuk mengetahui tingkat bahaya relatif yang ditimbulkan cangak abu terhadap keselamatan penerbangan dibandingkan jenis-jenis burung lainnya.

Hasil pengamatan ditabulasi dan diolah dengan Ms. Excel. Adapun kriteria untuk menyatakan besaran koloninya ditentukan menurut Bull (1974) yaitu jumlah individu selama 2 jam pengamatan dimana:

- Berjumlah > 1000 individui: sangat melimpah

- Berjumlah antara 200 - 1000 individu: melimpah

- Berjumlah antara 51 - 200 individu: sangat umum

- Berjumlah antara 21 - 50 individu: umum

- Berjumlah antara 7 - 20 individu: cukup umum

- Berjumlah antara 1-6 individu: tidak umum

\section{b. Aktivitas burung cangak abu selama berada dalam area BIY}

Parameter data yang diambil: besaran individu koloni yang datang; dan arah burung datang dan pergi, aktivitas anggota koloni selama berada di area bandara seperti berdiam diri, berburu mangsa, dan berjalan dan lain-lain. Data tersebut diambil melalui pengamatan langsung dari sisi barat runway dan sisi timur runway. Pengamatan dilakukan pada pukul 07.00-09.00 WIB dan 14.30-16.30 WIB, dengan menggunakan binokuler dan kamera dengan durasi pengamatan kurang lebih selama 2 jam per sesi. Hasil pengamatan dimasukkan dalam suatu tabel yang sudah dipersiapkan.

\section{Analisis data}

Data hasil pengamatannya dianalisis secara deskriptif-comparatif dibandingkan dengan hasil penelitian sebelumnya dan literatur sesuai obyek terkait.

\section{HASIL DAN PEMBAHASAN}

\section{Koloni burung cangak abu di Bandara Internasional Adisutjipto Yogyakarta}

Ringkasan hasil pengamatan keberadaan koloni burung cangak abu dan jenis buurung lainnya di area runway Bandara Internasional Adisutjipto Yogyakarta.yang diamati dari Watchroom Airport Rescue \& Fire Fighting Station (ARFF) tertuang pada Tabel 1.

Hampir tiap saat pada siang hari area runway JOG dikunjungi burung dari berbagai jenis, dan pada sore hari lebih banyak individu yang datang daripada pada pagi hari (Tabel 1). Frekuensi kedatangan tertinggi adalah burung wallet sapi, diikuti cangak abu, dan kuntul kerbau. Proporsi pengunjung yang terbanyak di pagi hari adalah cangak abu, diikuti wallet sapi dan bondol. Adapun pada sore hari walet sapi, diikuti cangak abu dan kuntul kerbau. Jadi berdasarkan gabungan antara frekuensi kedatangan dan proporsi jumlah individu yang mendatangi area JOG burung cangak abu relatif paling dominan. Burung yang cukup umum dan umum berdasarkan kriteria kemelimpahan Bull (1974) yaitu yang paling banyak jumlah individu perhari di lokasi pengamatan lebih dari 10 individu burung cangak abu (4 kali).

Kondisi lingkungan di area runway menyebabkan daya tarik bagi burung. Burung yang teramati berada di area rerumputan yang terpelihara, infrastructure bandara dan tempattempat adanya tanaman hias di tepi pagar (Gambar 1, 2 dan 3). Burung-burung kecil sering terlihat dari satu tempat ke tempat lain terkadang memotong 
Tabel 1. Jenis - jenis burung yang ditemukan di area landasan pesawat Bandara Internasional Adisutjipto Yogyakarta

\begin{tabular}{|c|c|c|c|c|c|c|c|c|c|c|c|c|c|c|c|c|c|c|c|c|c|c|c|}
\hline \multirow{3}{*}{$\begin{array}{c}\text { Jenis } \\
\text { Burung }\end{array}$} & \multicolumn{18}{|c|}{ Jumlah Individu Burung Pengamatan Tanggal 7 - 24 Agustus 2018} & \multirow{3}{*}{$\begin{array}{l}\mathrm{F} \\
\mathrm{r} \\
\mathrm{e} \\
\mathrm{k}\end{array}$} & \multirow{2}{*}{\multicolumn{2}{|c|}{$\begin{array}{l}\text { Jumlah } \\
\text { Individu }\end{array}$}} & \multirow{2}{*}{\multicolumn{2}{|c|}{$\%$-ase }} \\
\hline & \multicolumn{2}{|c|}{7} & \multicolumn{2}{|c|}{9} & \multicolumn{2}{|c|}{10} & \multicolumn{2}{|c|}{13} & \multicolumn{2}{|c|}{14} & \multicolumn{2}{|c|}{15} & \multicolumn{2}{|c|}{16} & \multicolumn{2}{|c|}{23} & \multicolumn{2}{|c|}{24} & & & & & \\
\hline & $\mathrm{P}$ & $\mathrm{S}$ & $\mathrm{P}$ & S & $\mathrm{P}$ & $\mathrm{S}$ & $\mathrm{P}$ & S & $\mathrm{P}$ & $\mathrm{S}$ & $\mathrm{P}$ & $\mathrm{S}$ & $\mathrm{P}$ & S & $\mathrm{P}$ & S & $\mathrm{P}$ & $\mathrm{S}$ & & $\mathrm{P}$ & S & $\mathrm{P}$ & S \\
\hline Burung gereja & 2 & 5 & 0 & 0 & 20 & 20 & 1 & 0 & 1 & 0 & 2 & 1 & 0 & 0 & 0 & 0 & 0 & 0 & 8 & 26 & 26 & 15,7 & 15,7 \\
\hline $\begin{array}{c}\text { Burung } \\
\text { Layang- layang }\end{array}$ & 3 & 0 & 0 & 0 & 0 & 0 & 0 & 0 & 0 & 2 & 0 & 0 & 0 & 4 & 0 & 1 & 0 & 0 & 4 & 3 & 7 & 1,81 & 4,2 \\
\hline Cangak abu & 12 & 0 & 17 & 17 & 7 & 5 & 9 & 13 & 1 & 1 & 3 & 0 & 3 & 2 & 1 & 0 & 0 & 4 & 14 & 53 & 42 & 32,1 & 25,4 \\
\hline Kareo padi & 2 & 1 & 0 & 0 & 0 & 1 & 3 & 1 & 2 & 0 & 1 & 0 & 5 & 2 & 3 & 1 & 1 & 0 & 12 & 17 & 6 & 10,3 & 3,63 \\
\hline Kuntul kerbau & 1 & 5 & 2 & 1 & 0 & 1 & 7 & 0 & 1 & 1 & 1 & 30 & 0 & 7 & 0 & 0 & 1 & 1 & 13 & 13 & 39 & 7,87 & 23,6 \\
\hline Bondol & 2 & 2 & 0 & 0 & 15 & 10 & 2 & 27 & 0 & 0 & 1 & 0 & 0 & 2 & 2 & 0 & 0 & 0 & 9 & 22 & 41 & 13,3 & 24,8 \\
\hline Penthet kelabu & 0 & 0 & 1 & 0 & 1 & 0 & 1 & 5 & 1 & 0 & 0 & 0 & 0 & 1 & 1 & 0 & 0 & 0 & 7 & 5 & 6 & 3,03 & 3,63 \\
\hline Kerak ungu & 0 & 0 & 0 & 0 & 0 & 0 & 0 & 0 & 0 & 0 & 1 & 0 & 0 & 0 & 3 & 4 & 0 & 0 & 3 & 4 & 4 & 2,24 & 2,42 \\
\hline Walet sapi & 0 & 0 & 3 & 3 & 1 & 3 & 5 & 2 & 2 & 5 & 1 & 10 & 7 & 10 & 3 & 6 & 2 & 8 & 16 & 22 & 47 & 13,3 & 28,4 \\
\hline & & & & & & al in & & & & & & & & & & & & & 65 & & 218 & 100 & 100 \\
\hline
\end{tabular}

runway. Sementara burung besar yaitu cangak abu $(100 \mathrm{~cm})$ dan kuntul kerbau $(65 \mathrm{~cm})$ (McKinnon dkk., 1998) mulai datang dan pergi selalu di area rerumputan walaupun saat dan kepergiannya terkadang memoton jalur runway. Berdasarkan hasil penelitian di atas diketahui bahwa burung cangak abu menjadi jenis burung yang relatif paling beresiko di JOG dibanding burung jenislainnya untuk keselamatan penerbangan, khususnya saat pesawat take off dan landing. Hal itu disebabkan jumlah individunya terbanyak dan persentase tertinggi, dan frekuensi kedatangannya tertinggi kedua setelah burung wallet sehingga frekuensi tautannya dengan lalu lintas pesawat juga menjadi relatif tertinggi. Perilaku burung di bandara dapat juga bervariasi dalam satu hari. Pada pertengahan hari kebanyakan burung berdiam diri di tempat istirahat, dan pada sore hari amulai kelihatan banyak yang beterbangan dan menjadi mata hari terbenam akan lebih banyak lagi yang beterbangan. Jadi pengelola bandara harus menyadari adanya fluktuasi pergerakan burung sekitar runway sepanjang hari (Baciuska and Ferdinand, 2017).

Setiap burung yang datang memanfaatkan kondisi lingkungan bandara dengan cara yang berbeda-beda. Burung tercatat paling banyak berada di sisi landasan yang tertutup rerumputan dan infrastructure serta tumbuhan semak di selasela bangungan atau infrastruktur yang ada untuk bertengger, mencari makanan atau beristirahat. Pada Gambar 1, 2 dan 3 adalah sebagian dari jenisjenis burung yang dijumpai di area runway JOG.

\section{Aktivitas burung cangak abu di Bandara Internasional Adisutjipto Yogyakarta}

Pengamatan aktivitas burung cangak abu dilakukan di sisi timur runway dan sisi barat runway yang hasilnya tertuang pada Tabel 2 .

Burung cangak abu beraktivitas dan hilir mudik di bandara hampir sepanjang hari, namun yang pagi hari lebih sedikit (rata-rata 6 individu) daripada sore hari (rata-rata 16 individu). Kaitan antara data kondisi cuaca cerah, hujan dan mendung dengan jumlah individu cangak abu yang datang masih sukar ditentukan (Tabel 2). Menurut Aschoff (1966) secara umum puncak aktivitas burung selama fajar dan senja. Banyak burung akan memaksimalkan aktivitas mereka selama waktu paling dingin (fajar). Ini memungkinkan mereka menghemat air dan mengurangi bahaya stres akibat panas. Aktivitas mereka kemudian akan menurun sepanjang hari ketika mereka menemukan tempat berlindung dari panas dan mencerna makanan mereka. Pola harian itu tidak bisa diterapkan untuk mengetahui kegiatan harian cangak abu karena burung ini hanya beberapa jam berada di area JOG dan tidak diikuti sepanjang hari.

\section{a. Aktivitas burung cangak abu di Bandara Internasional Adisutjipto Yogyakarta}

Pengamatan aktivitas burung cangak abu dilakukan di sisi timur runway dan sisi barat runway yang hasilnya tertuang pada Tabel 2 . 


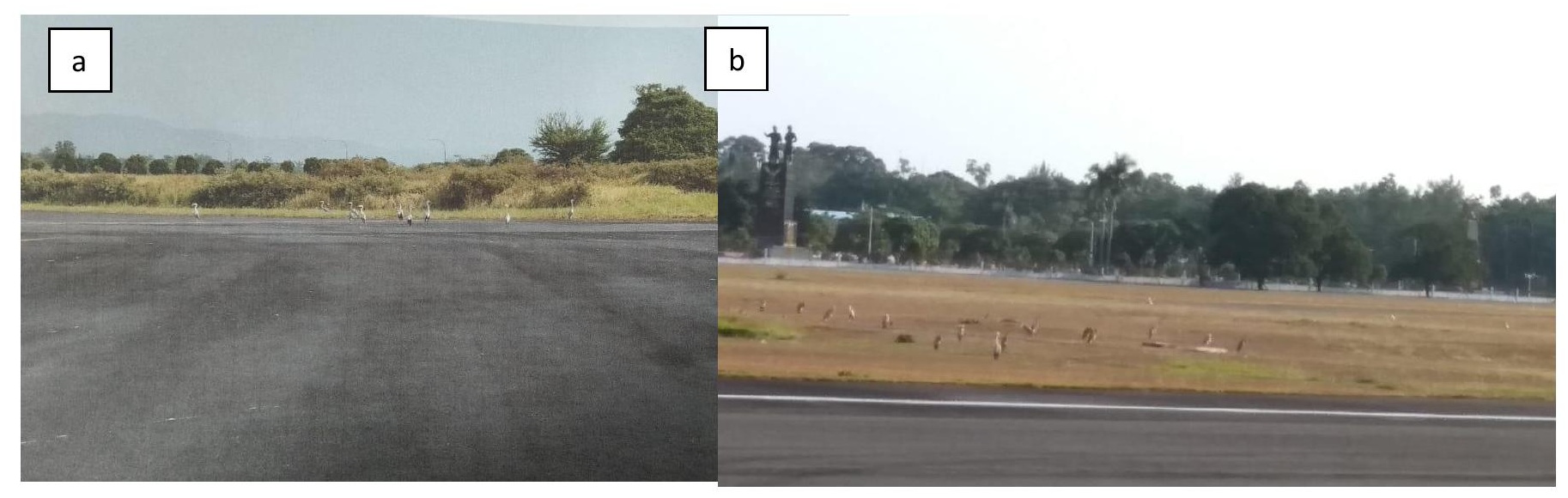

Gambar 1. Burung cangak abu (Ardea cinerea) sedang loafing (a) dan (b) di area runway dari arah barat (Dokumentasi tim peneliti, 2018).

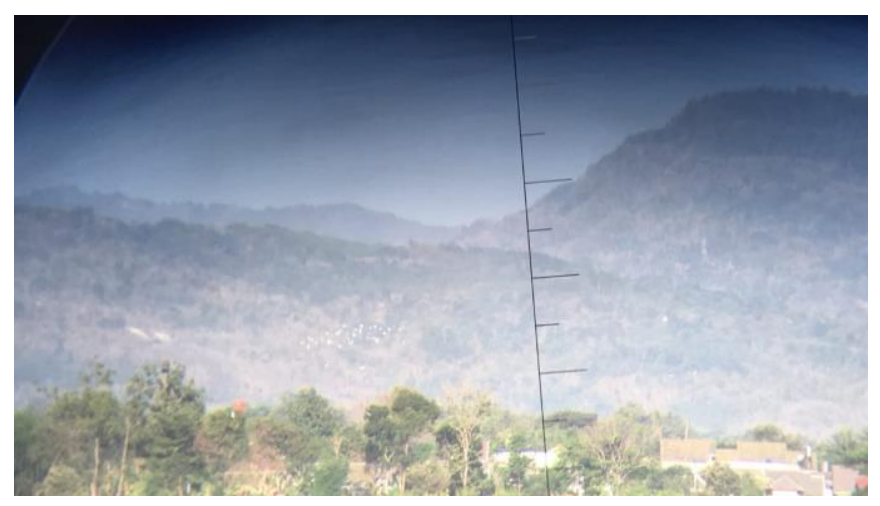

Gambar 2. Burung kuntul kerbau (Bulbucus iibis) sedang terbang di atas area runway (Dokumentasi tim peneliti, 2018).
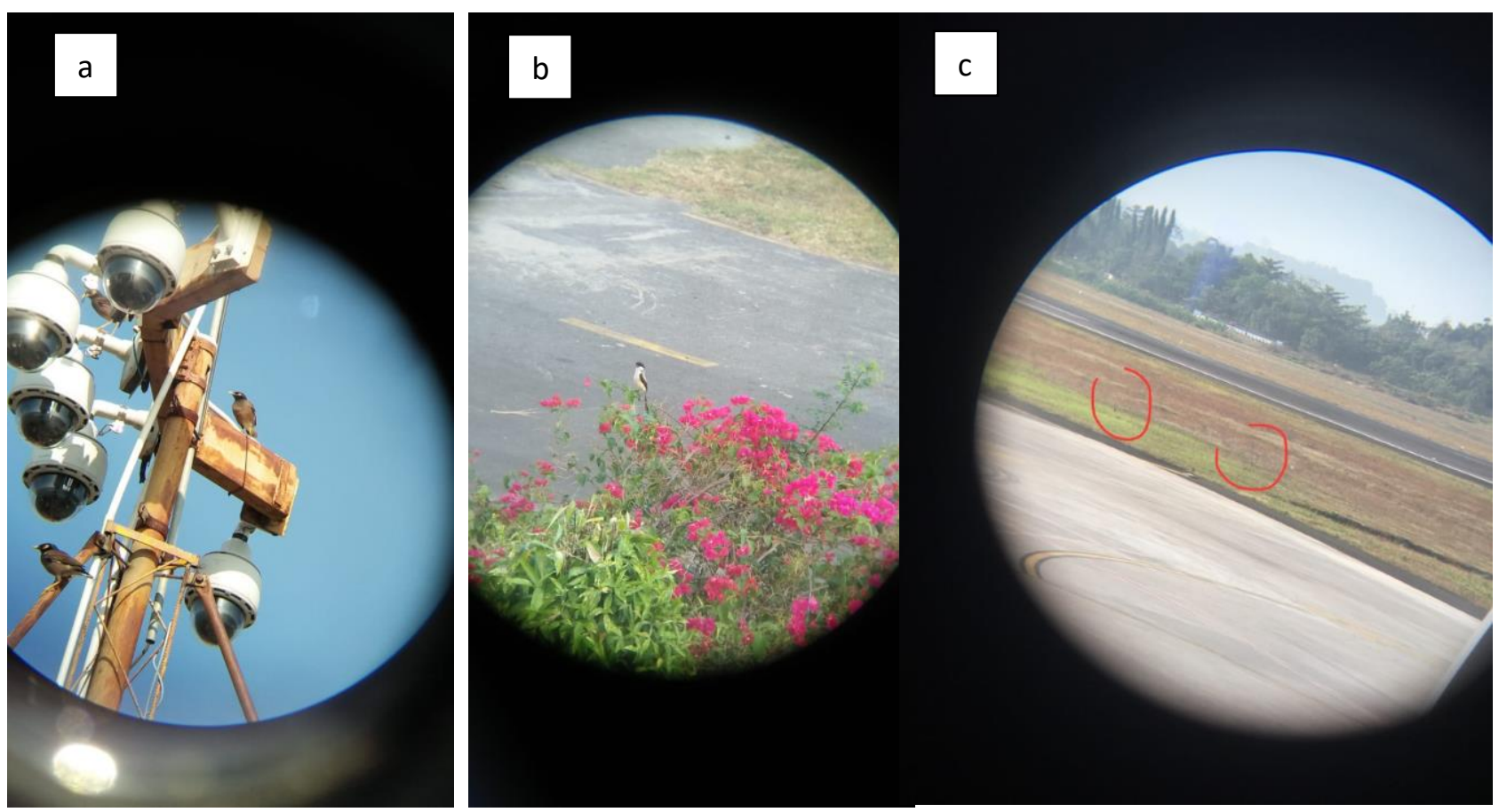

Gambar 3. a. Burung kerak ungu (Acridotheres tristis) sedang bertengger; b. Burung pentet kelabu (Larius schach) sedang bertengger; c. burung bondol (Lonchura sp) sedang mencari makan (Dokumentasi tim peneliti, 2018). 
Tabel 2. Pengamatan aktivitas cangak abu pengunjung di area sisi timur dan barat runway Bandara Internasional Adisutjipto Yogyakarta (JOG)

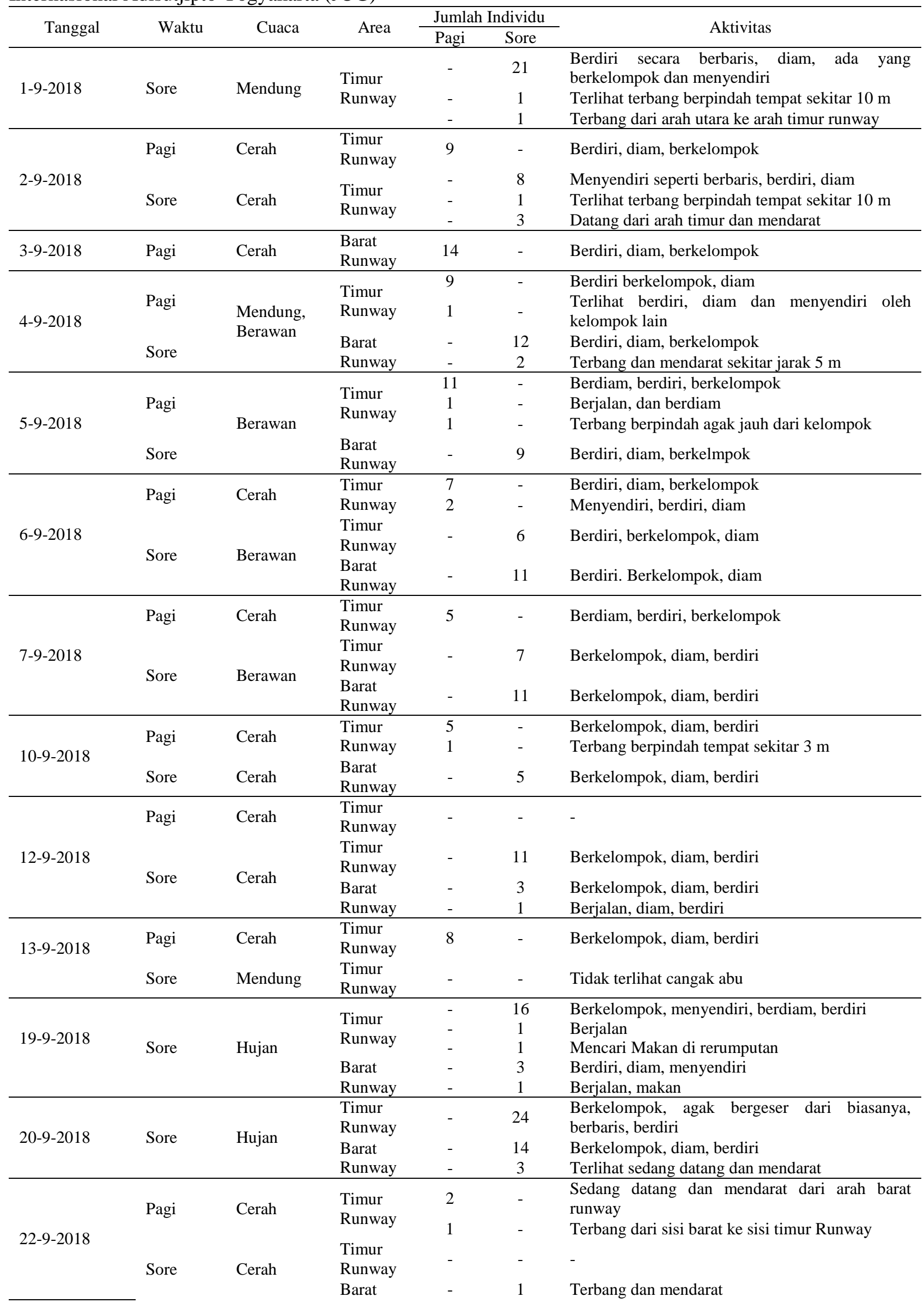




\begin{tabular}{|c|c|c|c|c|c|c|}
\hline & & & Runway & $\begin{array}{l}- \\
-\end{array}$ & $\begin{array}{l}1 \\
2 \\
2\end{array}$ & $\begin{array}{l}\text { Berjalan di rerumputan } \\
\text { Berdiri,diam, menyendiri } \\
\text { Terbang dari pohon sebelah barat runway }\end{array}$ \\
\hline \multirow{2}{*}{ 24-9-2018 } & \multirow{2}{*}{ Sore } & \multirow{2}{*}{ Cerah } & $\begin{array}{l}\text { Timur } \\
\text { Runway }\end{array}$ & - & 2 & Berkelompok, diam, berdiri \\
\hline & & & $\begin{array}{l}\text { Barat } \\
\text { Runway }\end{array}$ & - & 3 & Berkelompok, diam, berdiri \\
\hline \multirow{2}{*}{ 26-9-2018 } & \multirow{2}{*}{ Sore } & \multirow{2}{*}{ Berawan } & $\begin{array}{l}\text { Timur } \\
\text { Runway }\end{array}$ & - & 6 & Berkelompok, diam, berdiri \\
\hline & & & $\begin{array}{l}\text { Barat } \\
\text { Runway }\end{array}$ & - & 4 & Berkelompok, diam, berdiri \\
\hline \multirow{4}{*}{$27-9-2018$} & \multirow{4}{*}{ Sore } & \multirow{4}{*}{ Cerah } & Timur & - & - & - \\
\hline & & & Runway & - & 1 & Datang dan mendarat, diam \\
\hline & & & Barat & - & 1 & Berkelompok, diam, berdiri \\
\hline & & & Runway & - & 1 & Terbang dari semak sekitar dan mendarat \\
\hline \multirow{4}{*}{$28-9-2018$} & Pagi & Cerah & $\begin{array}{l}\text { Timur } \\
\text { Ranway }\end{array}$ & - & - & - \\
\hline & \multirow{3}{*}{ Sore } & \multirow{3}{*}{ Berawan } & $\begin{array}{l}\text { Timur } \\
\text { Runway }\end{array}$ & - & 4 & Berkelompok, diam, berdiri \\
\hline & & & Barat & - & 3 & Berkelompok, diam, berdiri \\
\hline & & & Runway & - & 1 & Berjalan, diam \\
\hline \multirow{3}{*}{$1-10-2018$} & \multirow{3}{*}{ Sore } & \multirow{3}{*}{ Berawan } & Timur & - & 1 & Berjalan, diam \\
\hline & & & Runway & - & 2 & Berkelompok, diam, berdiri \\
\hline & & & $\begin{array}{l}\text { Barat } \\
\text { Runway }\end{array}$ & - & 4 & Berkelompok, diam, berdiri \\
\hline \multirow{3}{*}{$3-10-2018$} & \multirow{3}{*}{ Sore } & \multirow{3}{*}{ Cerah } & $\begin{array}{l}\text { Timur } \\
\text { Runway }\end{array}$ & - & 2 & Berkelompok, diam, berdiri \\
\hline & & & Barat & - & 1 & Berjalan,diam \\
\hline & & & Runway & - & 1 & Terbang dari pohon disamping lalu mendarat \\
\hline \multirow{4}{*}{$5-10-2018$} & \multirow{4}{*}{ Sore } & \multirow{4}{*}{ Cerah } & $\begin{array}{l}\text { Timur } \\
\text { Runway }\end{array}$ & - & - & - \\
\hline & & & & - & 3 & Diam,berdiri, menyendiri \\
\hline & & & $\begin{array}{l}\text { Barat } \\
\text { Runway }\end{array}$ & - & 40 & $\begin{array}{l}\text { Terlihat dua koloni Cangak Abu yang sedang } \\
\text { terbang dari timur ke barat runway }\end{array}$ \\
\hline & & & & - & 1 & Berjalan, diam \\
\hline \multicolumn{3}{|c|}{ Jumlah individu } & & 73 & 274 & \\
\hline \multicolumn{3}{|c|}{ Rata-rata } & & 3,65 & 13,7 & \\
\hline
\end{tabular}

(Sumber data : Tim peneliti, 2018).

Setiap hari, pagi dan sore burung cangak abu secara berkelompok atau sendirian mendatangi dan pergi dari area JOG di area yang tertutup rerumputan (Tabel 2 dan Gambar 1). Burung ini terbang rendah dari/ke empat arah dengan kecepatan relatif pelan terkadang menyilang, di atas dan sejajar runway sangat mudah terlihat karena ukuran tubuhnya diantara burung lain pengunjung area bandara. Aktivitasnya selama di Bandara sebagian besar waktunya dihabiskan hanya berdiam diri tidak melakukan aktivitas apapun kecuali diam berdiri tidak jauh dari tempat mereka mendarat, menelisik bulu-bulu, hanya sesekali berjalan beberapa langkah dan sangat jarang kelihatan sedang mematuk seperti berburu. Menurut Cook (1978) di lokasi foraging berupa rerumputan terbuka terkadang sambil jalan memakan serangga besar atau rodent/mammal kecil. Namun karena sebagian besar waktunya di JOG adalah inaktif maka kegiatan seperti ini secara kategoris disebut kegiatan loafing. Kegiatan loafing, yaitu keadaan burung tidak aktif meliputi berbagai perilaku seperti tidur, bertengger, berdiri, membersihkan bulu dan buang air yang dilakukan di luar area teritori berbiak/roosting/nesting (Henson dan Hayward, 2010).

Burung cangak abu (Tabel 2) di area runway datang/pergi secara kelompok atau sendirian dari/ke arah barat daya, barat laut, timur laut dan timur arah runway. Selama di bandara mereka melakukan kegiatan loafing di antara kegiatan foraging dan nesting/roosting yang lokasinya di luar area Bandara. Cangak abu yang mendatangi JOG belum diketahui lokasi roosting/nesting dan lokasi foraging-nya, dan seberapa jauh antara lokasi roosting/nesting dan lokasi foraging-nya. Sebagai gambaran untuk cangak jenis lainnya yaitu cangak biru besar (Ardea herodias) terbang sampai $80 \mathrm{~km}$ ulang alik tiap hari dari tempat nesting/roosting koloni ke tempat feeding ground-nya/foraging dan sebaliknya (Praat, 1980). Di wilayah sampai sejauh beberapa kilometer sekitar JOG dijumpai lokasi roosting/nesting koloni sekitar JOG yaitu di area sebelah barat tidak jauh dari JOG, Kebun Binatang Gembiro Loka dan Kampus Universitas Gadjah Mada. Adapun lokasi feeding ground cangak abu 
dijumpai di area persawahan wilayah Ngemplak, Kecamatan Kalasan dan Kecamatan Cangkringan. Namun belum bisa dipastikan apakah koloni pengunjung area JOG adalah juga koloni cangak abu yang lokasi feeding dan nesting/roosting di tempat-tempat tersebut di atas.

Berdasarkan pengamatan langsung dan wawancara dengan pengelola bandara diketahui bahwa pengelola telah melaksanakan pengelolaan keberadaan satwa liar sesuai panduan pemerintah. Panduan itu tertuang dalam Surat Edaran yang dikeluarkan oleh Direktorat Jenderal Perhubungan Udara nomor SKEP / 42 / III / 2010, khususnya pasal 2 tentang manajemen bahaya hewan liar di bandar udara. Hal-hal yang dilakukan antara lain melakukan pemotongan rumput secara berkala, pengusiran dengan suara, semprotan air, dan patroli dengan armada mobil bird strike; namun demikian tetap saja masih ada kejadian bird strike di JOG itu yang diakibatkan terutama oleh burung cangak abu. Burung ini ukuran tubuhnya yang relatif terbesar, saat mendatangi dan pergi dari bandara terbang rendah, pelan dan arah terbangnya menyilang dan atau berdekatan dengan arah pesawat yang mendarat dan take off dari landasan, serta manuveirnya juga lamban di area runway menyebabkan resiko terjadi tabrakan juga relatif lebih besar dan kerusakan yang ditimbulkannya juga relatif terbesar diandingkan jenis buurung yang lain. Hasil penelitain ini memperkuat pernyataan pendapat para ahli (Cleary dan Dolbeer, 2005) bahwa walaupun pengelolaan habitat burung tampaknya menjadi yang paling efektif dalam jangka panjang, namun, pengelolaan habitat tidak selalu menjamin kontrol penuh atas keberadaan burung sehingga masih perlu dilengkapi dengan metode pengelolaan lainnya.

Konsep zonasi lokasi wilayah jelajah harian cangak abu sangat berguna untuk pengelolaan koloni ini. Burung cangak abu di bandara JOG diketahui ada tiga zona yaitu zona foraging/feeding, zona roosting/nesting, dan zona loafing. Walaupun keberadaan cangak abu di JOG sering diusir dan ditakut-takuti namun setiap hari datang ke bandara karena kemungkinan posisi bandara yang strategis dan kondisi lingkungan disukai koloni burung ini untuk loafing. Sementara zona roosting/nesting dan zona foraging/feeding berada di luar Bandara yang masih terjangkau untuk menjalankan aktivitas hariannya.

Menurut Emlen (1959), kegiatan loafing merupakan kegiatan di antara roosting/nesting dan foraging/feeding. Hal itulah yang nampaknya dilakukan oleh burung cangak abu di area runway Bandara. Pada pagi hari tanggal 22 September terlihat cangak abu terbang dari sisi barat ke sisi timur runway Bandara. Pada sore hari pada tanggal 1 dan 3 September (Tabel 3) dari arah timur dan timur laut Bandara beberapa cangak abu mendarat di sisi timur runway, dan tanggal 5 Oktober terlihat 2 koloni cangak abu terbang dari timur Bandara menuju ke sisi barat runway. Setelah diamati ternyata di bagian tenggara ada di kawasan Bandara terdapat lokasi bersarang (roosting /breeding ground) koloni cangak abu. Koloni cangak abu memanfaatkan keberadaan pepohonan yang tinggitinggi dan besar-besar untuk bersarang. Selain sebagai cangak abu, area yang cukup luas yang ditumbuhi pepohonan juga sebagai roosting/breeding ground jenis burung yang lain (Suripto dan Fauzy, 2018). Burung cangak abu meninggalkan area roosting/nesting untuk mencari makan ke zona feeding/foraging pada pagi hari sampai sore hari, lalu kembali ke roosting/feeding pada sore hari. Sebelum masuk ke pepohonan sarang mereka melakukan aktivitas loafing terlebih dahulu di area runway. Pada pagi hari sebelum berburu sebagian dari mereka singgah dulu di area runway untuk melakukan loafing, walaupun dari sisi jumlah dan frekuensinya lebih sedikit dibandingkan sore hari. Hasil pengamatan itu juga dapat diketahui bahwa habitat mencari makan (feeding ground) koloni cangak abu pengunjung runway Bandara JOG adalah di wilayah timur dan atau timur laut dari Bandara.

Secara umum adanya kecenderungan kejadian bird strike tetap terjadi di seluruh dunia. Menurut Manktelow (2000) penyebabnya antara lain kecenderungan pertambahan jumlah jenis dan jumlah individu burung yang mendatangi area airport, frekuensi penerbangan yang lebih canggih dan suaranya semakin rendah; dan area bandara yang menjadi bagian dari ekosistem di luarnya cenderung menjadi wilayah urban yang sangat ideal bagi banyak jenis burung yang kosmopolitan. Hal ini juga terjadi di bandara di Pulau Jawa, sekalipun keberadaan burung di Pulau Jawa cenderung menurun sebagai akibat bertambahnya angka konversi lahan dari lahan hijau menjadi lahan pemukiman, industri dan perdagangan, namun banyak jenis burung mampu beradaptasi dan bertahan hidup serta berkembang di wilayah suburban dan urban termasuk di area bandara dan sekitarnya sebagai habitat burung.

Kondisi area runway JOG yang luas, terbuka, tertutup rerumputan, berangin, juga dikelilingi oleh area terbuka hijau pepohonan yang relatif sepi dari kegiatan manusia; serta lokasinya yang strategis diantara zona foraging/feeding dan roosting/nesting menjadikan area JOG tempat ideal untuk loafing bagi cangak abu. 


\section{KESIMPULAN}

Keberadaan burung cangak abu (Ardea cinerea) di Bandara Adisutjipto berpotensi relatif terbesar menimbulkan kejadian bird strike dibanding burung jenis lainnya karena jumlah individu harian yang datang terbanyak, frekuensi kedatangannya tertinggi kedua setelah burung wallet, ukuran tubuhnya yang relatif terbesar, terbang rendah, terbang pelan dan manuvernya juga lamban serta terbang menyilang landasan.

Kondisi lingkungan area runway JOG yang luas, lapang terbuka, ditutupi hijauan rerumputan, berangin, aman dari predator, sepi jauh dari kegiatan manusia dan lokasinya yang strategis diantara zona roosting/nesting dan zona foraging/feeding menjadi lokasi yang ideal bagi koloni cangak abu untuk melakukan kegiatan harian loafing.

Berdasarkan hasil penelitian ini maka disarankan agar pengelola JOG meningkatkan kewaspadaan terhadap kemungkinan peningkatan kehadiran burung cangak abu, dan diharapkan selain menjalankan langkah-langkah yang tertulis pada panduan yang tertuang pada Surat Edaran Direktorat Jenderal Perhubungan Udara nomor SKEP / 42 / III / 2010, juga memperluas jangkauan pengelolaan populasi cangak abu di luar wilayah bandara JOG.

\section{DAFTAR PUSTAKA}

Agustono, 2017. Implementation of Birdstrike Management in Indonesia: Indonesia's Experience, http://www.aawhg.org/uploads/7/ 8/7/3/78739940/indonesians-aawhgpresentation-.pdf [Accessed on 15 Aug 2017].

Aschoff, J., 1966. Circadian Activity Pattern with Two Peaks. Ecology, 47(4).

Baciuska, C. and Ferdinand, S., 2017. Wildlife Hazard Assessment of the Frederick Municipal Airport 2016-2017. Loomacres Wildlife Management.

Badan Standardisasi Nasional, 2005. SNI 03-71122005 tentang Kawasan Keselamatan Operasi Penerbangan (KKOP). Jakarta.

Bull, J., 1974. Birds of New York State. Published by Doubleday/Natural History Press. Edited by Emanuel Levine. Cornell University Press. $622 \mathrm{pp}$

Cleary, E.C. and Dolbeer, R.A., 2005. Wildlife hazard management at airports: a manual for airport personnel 2nd edition - U.S. Department of Agriculture and U.S. Federal Aviation Administration, Sandusky, O.H. and Washington D.C.

Cook, D.C. 1978. Foraging Behaviour and Food of Grey Herons Ardea cinerea on the Ythan Estuary, Bird Study, 25(1):17-22.

Dove, C.J., Heacker, M. and Weigt, L., 2006. Bird Strike Committee USA/CANADA, 8th Annual meeting, St. Louis 25. https://digitalcommons.unl.edu/birdstrike2006/ 25/

Emlen J.R., J.T., 1959. Flocking Behavior in Birds. AUK 959: 60-170

Henson, S.M. and Hayward, J.L., 2010. The Mathematics of Animal Behavior: An Interdisciplinary Dialogue. November 2010. Notices of the American Mathematica Society 57(10): 1248-1258

MacKinnon, J., Phillips. K, van Balen, K., 1998. Burung-burung di Sumatra, Jawa, Bali dan Kalimantan. Seri Panduan Lapangan. Puslitbang LIPI. Bogor.

Manktelow, S. 2002. The Effect of Local Weather Conditions on Bird-Aircraft collision at British Airport. International Bird Strike Committee IBSC25/WP-BB4 Amsterdam, 17-21 April 2000.

Satriyono, A. 2008. Aktivitas dan penggunaan habitat burung pengganggu penerbangan di Kawasan Bandar Udara Internasional Juanda. Thesis, Institute Teknologi Sepuluh Nopember Surabaya.

Pranyoto, V.S. 2017. Populasi Burung Meningkat Bandara Adisutjipto Sempat Ditutup. Website Antara Yogya.

Pratt, H.M.1980. Direction and Timing of Great Blue Hron Foraging Flight from a California Colony: Implications for Social Facilitation of Food Finding. Wilson Bull., 92(4):489-496.

Sitompul, S.A., and Hanafi, A. 2017. Analisis Tabrak Burung Pada Leading Edge Dengan Metode Elemen Hingga. Jurnal Teknologi Kedirgantaraan. 2(2):25-29.

Sodhi, N.S., 2002. Competition in the Air: Birds Versus Aircraft. The Auk, 119(3), 587-595.

Suripto, B.A., dan Fauzy, N.H. 2018. The diurnal bird community in the vicinity of Adisutjipto International Airport Yogyakarta.: AIP Conference Proceedings 2002, 020008. 